\title{
Genomic profiling screens small molecules of metastatic prostate carcinoma
}

\author{
AXIANG XU and SHENGKUN SUN \\ Department of Urology, People's Liberation Army General Hospital, Beijing 100853, P.R. China
}

Received September 4, 2014; Accepted May 20, 2015

DOI: $10.3892 / 01.2015 .3472$

\begin{abstract}
The aim of the present study was to investigate the pathogenesis of metastatic prostate carcinoma, to find the metabolic pathways changed in the disease and to screen out the potential therapeutic drugs. GSE38241 was downloaded from Gene Expression Omnibus; the Geoquery package was applied to preprocessed expression profiling, and the differentially-expressed genes (DEGs) were selected with limma (linear regression model packages). Next, WikiPathways cluster analysis was performed for DEGs on a Gene Set Analysis Toolkit V2 platform, and DEGs with hypergeometric algorithms were calculated through gene set enrichment analysis. A total of 1,126 DEGs were identified between the normal prostate and metastatic prostate carcinoma. In addition, KPNA4, SYT1, PLCB1, SPRED1, MBNL2, RNF165, MEF2C, $M B N L 1, Z F P 36 L 1$ and $C E L F 2$, were found to be likely to play significant roles in the process of metastatic prostate carcinoma. The small molecules STOCK1N-35874 and 5182598 could simulate the state of normal cells well, while the small molecules MS-275 and quinostatin could simulate the state of metastatic prostate carcinoma cells. In conclusions, the small molecules STOCK1N-35874 and 5182598 were identified to be good potential therapeutic drugs for the treatment of metastatic prostate carcinoma, while the two small molecules MS-275 and quinostatin could cause metastatic prostate carcinoma.
\end{abstract}

\section{Introduction}

Prostate cancer is the most commonly occurring malignancy in men in developed Western countries, and is the second highest cause of cancer-associated mortality following lung tumors (1). Prostate cancer is associated with urinary dysfunction, which could cause pain, difficulty in urinating and problems during sexual intercourse (2). The cancer cells are able to use the lymphatic system or bloodstream to travel to other regions of

Correspondence to: $\mathrm{Dr}$ Axiang $\mathrm{Xu}$, Department of Urology, People's Liberation Army General Hospital, 28 Fuxing Road, Beijing 100853, P.R. China

E-mail: axiangxuaxx@163.com

Key words: metastatic prostate carcinoma, differentially expressed genes, microRNA, small molecules the body (3). However, in practice, the majority of cases of metastatic prostate carcinoma occur in the lymph nodes and the bones (4). It is unknown which regulatory mechanisms cause this transition, and thus far, no effective androgen-independent prostate cancer therapies have been developed (5).

Metastatic prostate carcinoma is classified as an adenocarcinoma, so there have been a number of studies on its pathogenesis. Numerous different genes, such as BRCAl and $B R C A 2$, have been implicated in metastatic prostate carcinoma (6). Yoshida et al found that BRCA1 and BRCA2 is a cancer precursor that can substantially affect the invasion of prostate cancer cells (7). Lee et al suggested that the PI3k/Akt signaling cascade is important for the migration of tumor cells. PI3K pathway activation by $\mathrm{Src}$ is known to result in increased cell survival. PI3K is a key regulator of the turnover of focal adhesion, and is essential for increasing the migration of cells (8). Senapati et al considered that during cell migration, when a cell moves forward and withdraws its rear edge, focal adhesions are disassembled at this edge. Macrophage inhibitory cytokine-1 (MIC-1) decreases the level of proliferation, invasion and migration in prostate cancer cells (9). The partial degradation of the extracellular matrix is required in prostate cancer invasion, which is an obligatory step in metastasis (10).

In order to investigate the pathogenesis of metastatic prostate carcinoma in the present study, a biological microarray was used to analyze the expression profiling and differentially-expressed genes (DEGs) of metastatic prostate carcinoma and normal prostate cells. In addition, bioinformatics methods were applied to find all metabolic and non-metabolic pathways changed in the prostate metastasis cancer cells, and to investigate the small molecule drugs restoring these pathways.

\section{Materials and methods}

Data source. GSE38241 (11), which included a 21 normal prostate sample microarray and an 18 metastatic prostate carcinoma sample microarray, was downloaded from the Gene Expression Omnibus (GEO) database (http://www.ncbi.nlm.nih.gov/geo/) of the National Center for Biotechnology Information. The platform for GSE38241 was GPL4133 Agilent-014850 Whole Human Genome Microarray 4x44K G4112F (Feature Number version).

Extraction of DEGs. The R software (v.2.13.0) (12) platform was applied to analyze the microarray data, and the Geoquery (13) and limma (14) packages were used to preprocess the data. The 
Table I. Top 10 significant differentially expressed genes in metastatic prostate carcinoma.

\begin{tabular}{|c|c|c|c|c|}
\hline Probe ID & adj.P.Val & P-value & $\log \mathrm{FC}$ & Gene symbol \\
\hline 28920 & $5.33 \times 10^{-29}$ & $3.55 \times 10^{-33}$ & 4.62666266 & TP63 \\
\hline 39959 & $4.19 \times 10^{-27}$ & $3.72 \times 10^{-31}$ & 3.08224052 & AOC 3 \\
\hline 41458 & $2.14 \times 10^{-26}$ & $2.85 \times 10^{-30}$ & 5.13220653 & KRT15 \\
\hline 25789 & $3.47 \times 10^{-26}$ & $5.60 \times 10^{-30}$ & 5.25910348 & SYNPO2 \\
\hline 39451 & $3.47 \times 10^{-26}$ & $6.17 \times 10^{-30}$ & 3.61424555 & TPM2 \\
\hline 34715 & $4.31 \times 10^{-26}$ & $8.61 \times 10^{-30}$ & 4.87226389 & $D E S$ \\
\hline 3135 & $7.89 \times 10^{-26}$ & $1.93 \times 10^{-29}$ & 3.71685606 & $-^{\mathrm{a}}$ \\
\hline 16065 & $1.24 \times 10^{-24}$ & $3.88 \times 10^{-28}$ & 3.82946930 & LMODI \\
\hline 10357 & $1.24 \times 10^{-24}$ & $4.14 \times 10^{-28}$ & 3.47528242 & SRD5A2 \\
\hline 41953 & $1.71 \times 10^{-24}$ & $6.14 \times 10^{-28}$ & 2.87266417 & KCNMB1 \\
\hline
\end{tabular}

The corresponding gene symbol for each probe ID was obtained from the GPL4133 files of the dataset GSE38241. aProbe not mapped to gene. adj.P.Val, adjusted P-value; FC, fold change.

Geoquery (15) package can quickly obtain microarray expression profiling from the GEO database, and the limma (16) package can statistically analyze the DEGs; this is the most popular method. First, the already preprocessed expression profiling was obtained with the Geoquery package, and then $\log _{2}$ transformation was performed. Finally the limma (linear regression model package) was applied to select the DEGs by differential comparison for the data of two groups.

Biological pathways analysis. In order to investigate the changes of metastatic prostate carcinoma at the molecular level, all metabolic and non-metabolic pathways were obtained from the public open access database, WikiPathways $(17,18)$. The Gene Set Analysis Toolkit V2 platform was used to perform WikiPathways cluster analysis for the DEGs (19) to obtain signal pathways that were changed in the metastatic prostate carcinoma cells.

Extraction of potential microRNAs. Based on gene annotation data in the MSigDB database (20), hypergeometric algorithms were used to calculate the DEGs through gene set enrichment analysis (GSEA). The Benjamini and Hochberg (BH) algorithm (21) was applied for correction, and finally, the potential microRNAs were identified.

Expression profiling of small molecules. The Connectivity Map (CMap) database stores the expression data of the whole genome-wide transcription of human cells treated with bioactive small molecules, including a total of 6,100 groups of small molecule interference experiments (small interfering groups and normal control groups) and 7,056 expression profiles (22). The gene expression differences of normal prostate cells and prostate cancer cells were analyzed and compared with the DEGs caused by these small interfering expression genes, in order to attempt to identify small molecules similar or opposite to the expression difference of normal prostate cells. The DEGs of normal prostate cells and prostate cancer cells were divided into two categories, the upregulated genes and the downregulated genes, and a total of 500 most significant probes were selected respectively. The enrichment value was obtained through GSEA (23) and comparison with the DEGs was performed by small molecules in the CMAP database. The value ranged between -1 and 1 , and the closer the value to 1 , the more able the small molecules were to simulate the state of normal prostate cells; by contrast, the closer the value to -1 , the more the small molecules were able to simulate the state of the prostate cancer cells.

Statistical analysis. Using limma package in $\mathrm{R}$, the expression profiling of normal prostate cells and metastatic prostate carcinoma cells was analyzed with a t-test modified by the Bayesian model (24). The corresponding P-value was calculated for all genes after the t-test, and the P-value was corrected with the $\mathrm{BH}$ algorithm. A P-value of $<1 \times 10^{-8}$ was selected to indicate a significant threshold.

\section{Results}

Identification of DEGs. Following analysis of expression profiling, a total of 1,126 DEGs were identified, including 880 known genes (Table I).

Bio-pathways changed in metastatic prostate carcinoma. In order to investigate the bio-pathway internal changes in metastatic prostate carcinoma cells, WikiPathways sub-pathway enrichment analysis was performed for the DEGs. The pathways with a P-value of $<0.0001$, and at least two genes in the pathway were selected as the significantly changed pathways (Table II).

Extraction of potential microRNAs. There are two methods for regulating gene translation, one is using the transcriptional level and the other is the regulation of the stability of RNA by microRNAs to regulate gene expression. So the analysis of potential microRNA regulation was also of particular importance in the present study, and the potential microRNAs were shown in Table III.

Combined with the potential microRNAs and DEGs, a microRNA-gene regulatory network was constructed (Fig. 1).

The DEGs subjected to more microRNAs in metastatic prostate carcinoma may play more important roles. Therefore, 
Table II. Bio-pathways changed in metastatic prostate carcinoma.

\begin{tabular}{lcr}
\hline Pathway & Count & P-value \\
\hline Muscle cell TarBase & 35 & $9.72 \times 10^{-11}$ \\
Lymphocyte TarBase & 39 & $1.06 \times 10^{-10}$ \\
Adipogenesis & 19 & $3.36 \times 10^{-10}$ \\
Focal adhesion & 22 & $3.97 \times 10^{-10}$ \\
Epithelium TarBase & 27 & $1.86 \times 10^{-8}$ \\
Arrhythmogenic right ventricular cardiomyopathy & 15 & $5.37 \times 10^{-8}$ \\
Integrin-mediated cell adhesion & 12 & $1.00 \times 10^{-5}$ \\
miRNAs in muscle cell differentiation & 6 & $2.00 \times 10^{-4}$ \\
AGE-RAGE pathway & 9 & $2.00 \times 10^{-4}$ \\
Androgen receptor signaling pathway & $9.00 \times 10^{-4}$ \\
TGF $\beta$ signaling pathway & 10 & $3.00 \times 10^{-4}$ \\
Myometrial relaxation and contraction pathways & 12 & $8.00 \times 10^{-4}$ \\
Angiogenesis & 12 & $8.00 \times 10^{-4}$ \\
Nuclear receptors & 5 & $8.00 \times 10^{-4}$
\end{tabular}

AGE-RAGE, advanced glycation end products (AGE)-receptor for AGE; miRNA, microRNA; TGF, transforming growth factor.

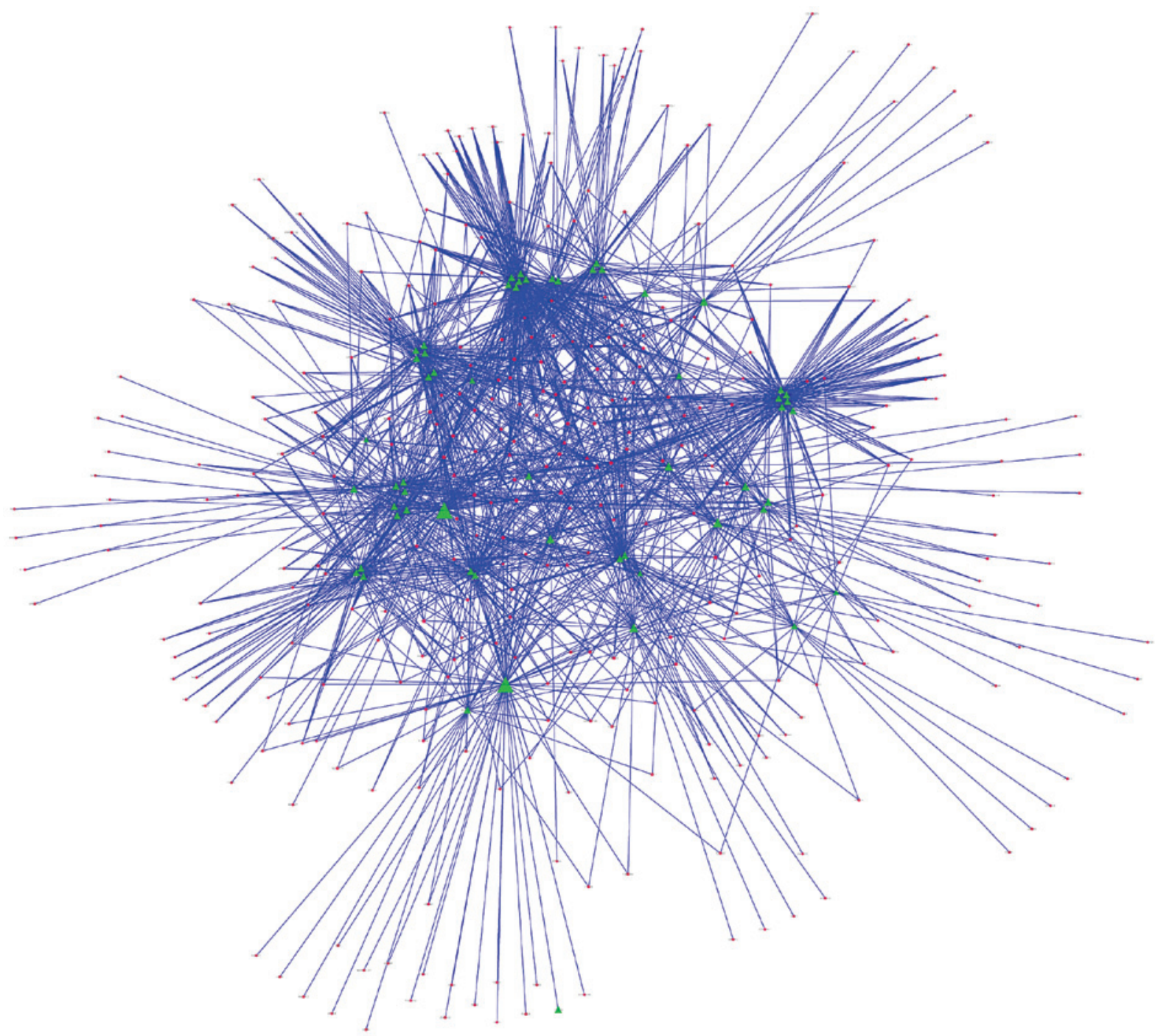

Figure 1. microRNA-gene regulatory network. The red nodes represent differentially-expressed genes (DEGs), the green nodes represent potential microRNAs, the triangular nodes represent microRNAs or DEGs regulated by $\geq 8$ microRNAs, and the lines represent regulation between microRNAs and DEGs. The more lines on the nodes, the larger the nodes. 
Table III. Potential miRNAs in metastatic prostate carcinoma.

\begin{tabular}{|c|c|c|}
\hline Target sequence & Potential microRNA & P-value \\
\hline hsa_GTGCCTT & miR-506 & $4.74 \times 10^{-22}$ \\
\hline hsa_TATTATA & $\operatorname{miR}-374$ & $1.52 \times 10^{-13}$ \\
\hline hsa_AATGTGA & miR-23A, miR-23B & $1.35 \times 10^{-12}$ \\
\hline hsa_TGCTGCT & miR-15A, miR-16, miR-15B, miR-195, miR-424, miR-497 & $2.10 \times 10^{-12}$ \\
\hline hsa_TGCCTTA & $\operatorname{miR}-124 \mathrm{~A}$ & $6.65 \times 10^{-12}$ \\
\hline hsa_ACTTTAT & miR-142-5P & $1.42 \times 10^{-11}$ \\
\hline hsa_TTTGCAC & miR-19A, miR-19B & $1.42 \times 10^{-11}$ \\
\hline hsa_TGTTTAC & miR-30A-5P, miR-30C, miR-30D, miR-30B, miR-30E-5P & $9.49 \times 10^{-11}$ \\
\hline hsa_ATGTACA & $\operatorname{miR}-493$ & $9.49 \times 10^{-11}$ \\
\hline hsa_GCAAAAA & miR-129 & $2.01 \times 10^{-10}$ \\
\hline hsa_TTGCCAA & $\operatorname{miR}-182$ & $2.01 \times 10^{-10}$ \\
\hline hsa_CTATGCA & miR-153 & $6.35 \times 10^{-10}$ \\
\hline hsa_TGAATGT & miR-181A, miR-181B, miR-181C, miR-181D & $1.68 \times 10^{-9}$ \\
\hline hsa_ACATTCC & miR-1, miR-206 & $2.16 \times 10^{-9}$ \\
\hline hsa_CTTTGCA & $\operatorname{miR}-527$ & $2.39 \times 10^{-9}$ \\
\hline hsa_AAGCACT & $\mathrm{miR}-520 \mathrm{~F}$ & $3.42 \times 10^{-9}$ \\
\hline hsa_TGCTTTG & miR-330 & $5.23 \times 10^{-9}$ \\
\hline hsa_ACTGTGA & miR-27A, miR-27B & $9.22 \times 10^{-9}$ \\
\hline hsa_GTGCCAA & miR-96 & $1.42 \times 10^{-8}$ \\
\hline hsa_AAAGGGA & miR-204, miR-211 & $2.37 \times 10^{-8}$ \\
\hline hsa_TGGTGCT & miR-29A, miR-29B, miR-29C & $2.58 \times 10^{-8}$ \\
\hline hsa_GTATTAT & miR-369-3P & $3.53 \times 10^{-8}$ \\
\hline hsa_CATGTAA & $\operatorname{miR}-496$ & $6.07 \times 10^{-8}$ \\
\hline hsa_CTTTGTA & miR-524 & $7.03 \times 10^{-8}$ \\
\hline hsa_AGGAAGC & miR-516-3P & $1.09 \times 10^{-7}$ \\
\hline hsa_TGCACTG & miR-148A, miR-152, miR-148B & $1.98 \times 10^{-7}$ \\
\hline hsa_GCTTGAA & $\operatorname{miR}-498$ & $2.74 \times 10^{-7}$ \\
\hline hsa_CAGTATT & miR-200B, miR-200C, miR-429 & $3.16 \times 10^{-7}$ \\
\hline hsa_GTGACTT & miR-224 & $4.73 \times 10^{-7}$ \\
\hline hsa_TGTGTGA & miR-377 & $5.33 \times 10^{-7}$ \\
\hline hsa_TTGCACT & miR-130A, miR-301, miR-130B & $5.71 \times 10^{-7}$ \\
\hline hsa_ACCAAAG & $\operatorname{miR}-9$ & $9.58 \times 10^{-7}$ \\
\hline
\end{tabular}

miRNA, microRNA.

Table IV. Differentially-expressed genes and their regulatory microRNA numbers.

\begin{tabular}{lc}
\hline Gene & Regulatory microRNA numbers \\
\hline KPNA4 & 8 \\
EYA1 & 8 \\
SYT1 & 8 \\
PLCB1 & 8 \\
SPRED1 & 8 \\
MBNL2 & 13 \\
RNF165 & 12 \\
MEF2C & 8 \\
MBNL1 & 8 \\
ZFP36L1 & 10 \\
CELF2 & 8 \\
\hline
\end{tabular}

the DEGs regulated by $\geq 8$ microRNAs were screened out to construct a secondary regulatory network (Fig. 2).

Extraction of small effected molecules. The ultimate goal of the present study was to provide aid in the treatment of metastatic prostate carcinoma, and one of the methods used to do this was to investigate the possible small molecule drugs for treatment of prostate metastatic carcinoma. The expressional difference between normal prostate cells and metastatic prostate carcinoma cells was analyzed, and then compared with the DEGs affected by small molecules, hoping to find the small molecule similar or opposite to the gene in the metastatic prostate carcinoma cells or normal cells. The 20 small molecules with the strongest correlation (P-value as minimum) are shown in Table IV.

As shown in Table V, the small molecules STOCK1N-35874 (enrichment, 0.989) and 5182598 (enrichment, 0.979) were able 
Table V. Small effected molecules in metastatic prostate carcinoma.

\begin{tabular}{|c|c|c|}
\hline CMap name & Enrichment value & $\mathrm{P}$-value \\
\hline Geldanamycin & 0.752 & $<0.00001$ \\
\hline $15-\delta$ prostaglandin $\mathrm{J} 2$ & 0.736 & $<0.00001$ \\
\hline LY-294002 & -0.335 & $<0.00001$ \\
\hline Trichostatin A & -0.265 & $<0.00001$ \\
\hline Sirolimus & -0.327 & 0.00008 \\
\hline MG-262 & 0.960 & 0.00010 \\
\hline STOCK1N-35874 & 0.989 & 0.00016 \\
\hline Diltiazem & -0.835 & 0.00032 \\
\hline Rosiglitazone & 0.537 & 0.00038 \\
\hline MS-275 & -0.988 & 0.00040 \\
\hline Hesperetin & -0.810 & 0.00056 \\
\hline Heptaminol & 0.809 & 0.00060 \\
\hline 5182598 & 0.979 & 0.00076 \\
\hline Fluphenazine & -0.445 & 0.00113 \\
\hline Bumetanide & 0.829 & 0.00127 \\
\hline Dinoprost & 0.823 & 0.00161 \\
\hline Acemetacin & 0.822 & 0.00167 \\
\hline Fenoprofen & -0.695 & 0.00197 \\
\hline Nifuroxazide & -0.807 & 0.00267 \\
\hline Quinostatin & -0.965 & 0.00280 \\
\hline
\end{tabular}

CMap, Connectivity Map.

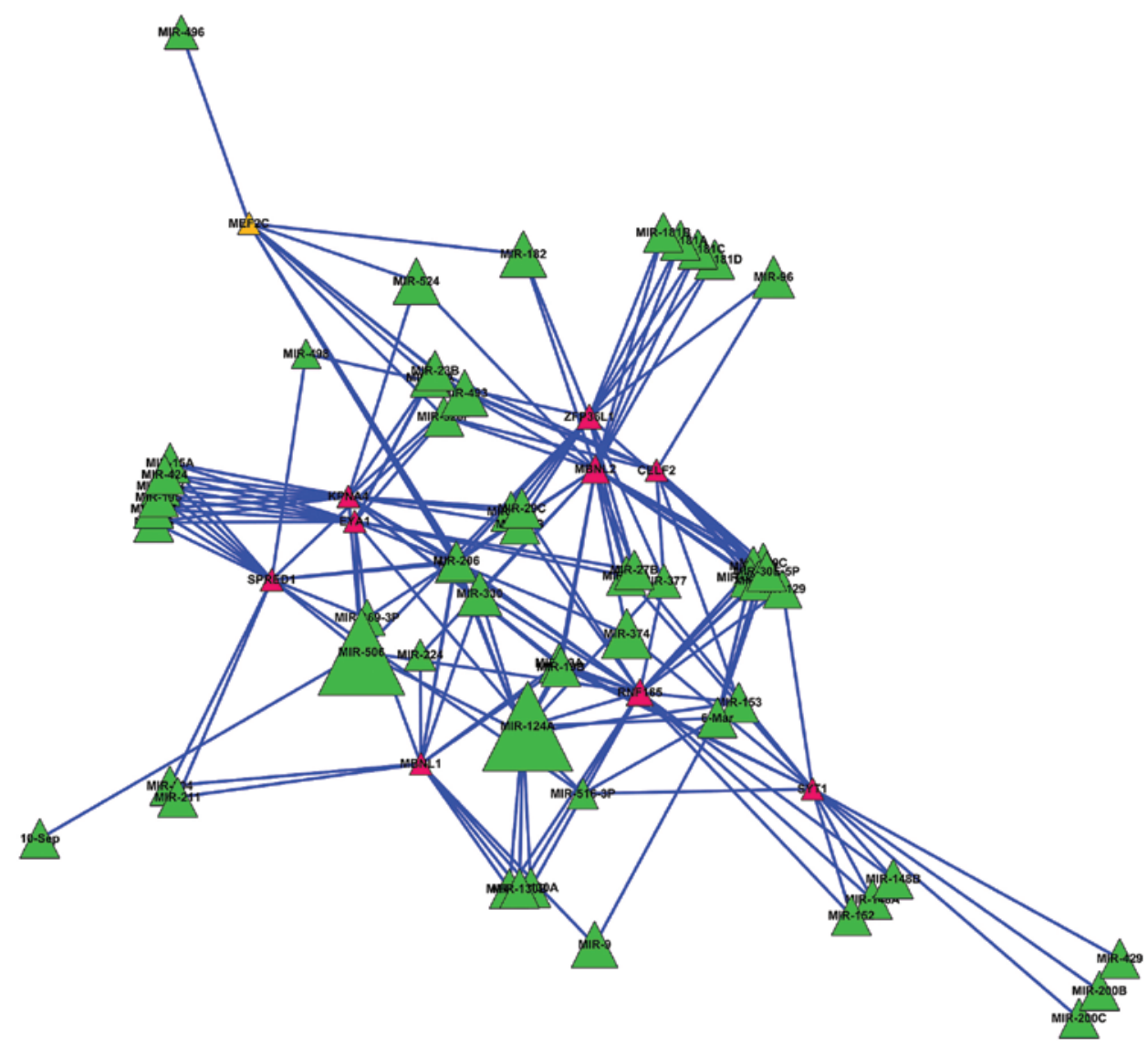

Figure 2. Secondary regulatory network. The red nodes represent differentially-expressed genes (DEGs), the green nodes represent potential microRNAs, the trianglular nodes represent microRNAs or DEGs regulated by $\geq 8$ microRNAs, and the lines represent regulation between microRNAs and DEGs. The more lines on the nodes, the larger the nodes. 
to simulate the state of the normal cells, indicating that these two small molecules were good potential therapeutic drugs for the treatment of metastatic prostate carcinoma. Meanwhile, the small molecules MS-275 (enrichment, -0.988) and quinostatin (enrichment, -0.965 ) could simulate the state of the metastatic prostate carcinoma cells, indicating that these two small molecules could cause metastatic prostate carcinoma.

\section{Discussion}

Prostate cancer is a malignancy that can occur in the prostate tissue of men. As of 2011, prostate cancer is the second most commonly diagnosed cancer and the sixth leading cause of cancer-associated mortality in men worldwide (25). The incidence of prostate cancer has clear geographical and ethnic differences. In Europe and other developed countries and regions, it is the most common male cancer, while in the USA, it is the second leading cause of cancer-associated mortality in men following lung cancer. In Asia, the incidence of prostate cancer is lower compared with Western countries, but this level has shown a rapidly increasing trend in recent years (26). Additionally, the cancer cells may metastasize from the prostate to other regions of the body, which can cause more harm. Therefore, it is of great significance for human health to study the pathogenesis of metastatic prostate carcinoma. The original study on GSE38241 data mainly studied and discussed the DNA modification in metastatic prostate carcinoma, however the present study focused on the gene expression of the disease. A total of 1,126 DEGs and a number of significantly changed biological pathways were identified. In addition, KPNA4, SYT1, PLCB1, SPRED1, MBNL2, RNF165, $M E F 2 C, M B N L 1, Z F P 36 L 1$ and $C E L F 2$ were found to be likely to play significant roles in the process of metastatic prostate carcinoma, according to their functions. Finally the small molecules STOCK1N-35874 and 5182598 were identified as good potential therapeutic drugs for the treatment of metastatic prostate carcinoma, while the two small molecules MS-275 and quinostatin could cause metastatic prostate carcinoma.

WikiPathways pathway clustering showed that the changes in a series of important signaling pathways in metastatic prostate carcinoma result in the changes of surface binding and cell morphogenesis in the disease, causing the easy migration of cancer cells in the body. Certain changes in surface binding, including focal adhesion, epithelium TarBase and the integrin-mediated cell adhesion pathway, can promote prostate cancer cells to more easily separate from the lesion and thus transfer to another region of the body (11). Certain changes in muscle cell TarBase, miRNAs in muscle cell differentiation, myometrial relaxation and contraction pathways mean that metastatic cells may be biased to muscle cell differentiation, causing a stronger ability to move. Certain signaling pathway changes, such as changes in the advanced glycation end products (AGE)-receptor for AGE pathway, the androgen receptor signaling pathway, the transforming growth factor $\beta$ signaling pathway and the nuclear receptors pathway, can result in the changes of downstream genes. The angiogenesis pathway is likely to provide convenience for the transfer of cancer cells, while adipogenesis is associated with energy regulation $(27,28)$. The changes to the lymphocyte TarBase aid the migrated cells in escaping immune attack (29). It is notable that metastatic prostate carcinoma not only damages the prostate cells, but also damages the other organs in the body and causes a series of complications, such as skeletal abnormalities.

In addition, as a large number of DEGs in metastatic prostate carcinoma may have the same transcription factor targets and microRNA regulation targets, these loci may play significant roles in the regulation of gene expression. Among these genes, MBNL1, MBNL2 and CELF2 regulate the alternative splicing of genes (30-32), KPNA4 is a localization signal protein in the cytoplasm (33), and ZFP36L1 is an important transcription factor response to growth factors (34). SYT1 is a $\mathrm{Ca}^{2+}$ signaling reception protein in the cytoplasmic membrane (35), PLCB1 catalyzes phosphatidylinositol-4,5-bisphosphate to inositol-1,4,5-trisphosphate and diacylglycerol (36), and SPREDI regulates intracellular signaling pathway mitogen-activated protein kinase activation (37). RNF165 and $M E F 2 C$ regulate cell movement (38). These genes are all likely to play important roles in the process of metastatic prostate carcinoma according to their functions.

Based on CMap database, a series of small molecules was obtained in the present study. STOCK1N-35874 is a cytotoxic quinoline alkaloid that inhibits the DNA enzyme topoisomerase, which is isolated from the bark and stem of Camptotheca acuminata (39). STOCK1N-35874 showed marked anticancer activity in preliminary clinical trials, and its analogues have been used in cancer chemotherapy $(40,41)$. 5182598 is considered to be an important anticancer drug from the group of benzylisoquinoline alkaloids (42). These two small molecules are able to repair the damaged metabolic pathways in metastatic prostate carcinoma, and are good potential therapeutic drugs for the treatment of metastatic prostate carcinoma.

\section{References}

1. Marks LS, Fradet Y, Deras IL, Blase A, Mathis J, Aubin SM, Cancio AT, Desaulniers M, Ellis WJ, Rittenhouse H, et al: PCA3 molecular urine assay for prostate cancer in men undergoing repeat biopsy. Urology 69: 532-535, 2007.

2. Andriole GL, Crawford ED, Grubb RL III, Buys SS, Chia D, Church TR, Fouad MN, Isaacs C, Kvale PA, Reding DJ, et al: Prostate cancer screening in the randomized prostate, lung, colorectal, and ovarian cancer screening trial: Mortality results after 13 years of follow-up. J Natl Cancer Inst 104: 125-132, 2012.

3. Schröder FH, Hugosson J, Roobol MJ, Tammela TL, Ciatto S, Nelen V, Kwiatkowski M, Lujan M, Lilja H, Zappa M, et al: Prostate-cancer mortality at 11 years of follow-up. N Engl J Med 366: 981-990, 2012.

4. Alhasan AH, Kim DY, Daniel WL, WatsonE, Meeks JJ, Thaxton CS and Mirkin CA: Scanometric MicroRNA array profiling of prostate cancer markers using spherical nucleic acid-gold nanoparticle conjugates. Anal Chem 84: 4153-4160, 2012.

5. Hessels D, Klein Gunnewiek JMT, van Oort I, Karthaus HF, van Leenders GJ, van Balken B, Kiemeney LA, Witjes JA and Schalken JA: DD3 (PCA3)-based molecular urine analysis for the diagnosis of prostate cancer. Eur Urol 44: 8-15, 2003.

6. Struewing JP, Hartge P, Wacholder S, Baker SM, Berlin M, McAdams M, Timmerman MM, Brody LC and Tucker MA: The risk of cancer associated with specific mutations of BRCA1 and BRCA2 among Ashkenazi Jews. NEngl J Med 336: 1401-1408, 1997.

7. Yoshida S, Tsutsumi S, Muhlebach G, Sourbier C, Lee MJ, Lee S, Vartholomaiou E, Tatokoro M, Beebe K, Miyajima N, et al: Molecular chaperone TRAP1 regulates a metabolic switch between mitochondrial respiration and aerobic glycolysis. Proc Natl Acad Sci USA 110: E1604-E1612, 2013.

8. Lee C, Zhang Q, Zi X, Dash A, Soares MB, Rahmatpanah F, Jia Z, McClelland M and Mercola D: TGF- $\beta$ mediated DNA methylation in prostate cancer. Transl Androl Urol 1: 78-88, 2012. 
9. Senapati S, Rachagani S, Chaudhary K, Johansson SL, Singh RK and Batra SK: Overexpression of macrophage inhibitory cytokine-1 induces metastasis of human prostate cancer cells through the FAK-RhoA signaling pathway. Oncogene 29: 1293-1302, 2010.

10. Jin JK, Dayyani F and Gallick GE: Steps in prostate cancer progression that lead to bone metastasis. Int J Cancer 128: 2545-2561, 2011.

11. Aryee MJ, Liu W, Engelmann JC, Nuhn P, Gurel M, Haffner MC, Esopi D, Irizarry RA, Getzenberg RH, Nelson WG, et al: DNA methylation alterations exhibit intraindividual stability and interindividual heterogeneity in prostate cancer metastases. Sci Transl Med 5: 169ra110, 2013.

12. R Development Core Team: R: A Language and Environment for Statistical Computing. http://www.r-project.org/. R Foundation for Statistical Computing, Vienna, Austria, 2008.

13. Davis S and Meltzer PS: GEOquery: A bridge between the gene expression omnibus (GEO) and BioConductor. Bioinformatics 23: 1846-1847, 2007.

14. Diboun I, Wernisch L, Orengo CA and Koltzenburg M: Microarray analysis after RNA amplification can detect pronounced differences in gene expression using limma. BMC Genomics 7: 252, 2006.

15. Barrett T, Troup DB, Wilhite SE, Ledoux P, Evangelista C, Kim IF, Tomashevsky M, Marshall KA, Phillippy KH, Sherman PM, et al: NCBI GEO: Archive for functional genomics data sets-10 years on. Nucleic Acids Res 39: D1005-D1010, 2011

16. Smyth GK: Linear models and empirical bayes methods for assessing differential expression in microarray experiments. Stat Appl Genet Mol Biol 3: Article 3, 2004.

17. Kelder T, van Iersel MP, Hanspers K, Kutmon M, Conklin BR, Evelo CT and Pico AR: WikiPathways: Building research communities on biological pathways. Nucleic Acids Res 40: D1301-D1307, 2012.

18. Pico AR, Kelder T, van Iersel MP, Hanspers K, Conklin BR and Evelo C: WikiPathways: Pathway editing for the people. PLoS Biol 6: e184, 2008

19. Zhang B, Kirov S and Snoddy J: WebGestalt: An integrated system for exploring gene sets in various biological contexts. Nucleic Acids Res 33: W741-W748, 2005.

20. Liberzon A, Subramanian A, Pinchback R, Thorvaldsdóttir H, Tamayo P and Mesirov JP: Molecular signatures database (MSigDB) 3.0. Bioinformatics 27: 1739-1740, 2011.

21. Benjamini $\mathrm{Y}$ and Hochberg Y: Controlling the false discovery rate: A practical and powerful approach to multiple testing. J Roy Statist Soc Ser B (Methodological) 57: 289-300, 1995.

22. Lamb J, Crawford ED, Peck D, Modell JW, Blat IC, Wrobel MJ, Lerner J, Brunet JP, Subramanian A, Ross KN, et al: The Connectivity Map: Using gene-expression signatures to connect smal molecules, genes, and disease. Science 313: 1929-1935, 2006.

23. Subramanian A, Tamayo P, Mootha VK, Mukherjee S, Ebert BL, Gillette MA, Paulovich A, Pomeroy SL, Golub TR, Lander ES et al: Gene set enrichment analysis: A knowledge-based approach for interpreting genome-wide expression profiles. Proc Natl Acad Sci USA 102: 15545-15550, 2005.

24. Baldi P and Long AD: A Bayesian framework for the analysis of microarray expression data: Regularized t-test and statistical inferences of gene changes. Bioinformatics 17: 509-519, 2001

25. Jemal A, Bray F, Center MM, Ferlay J, Ward E and Forman D: Global cancer statistics. CA Cancer J Clin 61: 69-90, 2011.

26. Siegel R, Naishadham D and Jemal A: Cancer statistics, 2012. CA Cancer J Clin 62: 10-29, 2012
27. Amankwah EK, Sellers TA and Park JY: Gene variants in the angiogenesis pathway and prostate cancer. Carcinogenesis 33: $1259-1269,2012$

28. Hinoi E, Nakamura Y, Takada S, Fujita H, Iezaki T, Hashizume S, Takahashi S, Odaka Y, Watanabe T and Yoneda Y: Growth differentiation factor-5 promotes brown adipogenesis in systemic energy expenditure. Diabetes 63: 162-175, 2013.

29. Rivoltini L, Carrabba M, Huber V, Castelli C, Novellino L, Dalerba P, Mortarini R, Arancia G, Anichini A, Fais S, et al: Immunity to cancer: attack and escape in T lymphocyte-tumor cell interaction. Immunol Rev 188: 97-113, 2002.

30. Lin X, Miller JW, Mankodi A, Kanadia RN, Yuan Y, Moxley RT, Swanson MS and Thornton CA: Failure of MBNL1-dependent post-natal splicing transitions in myotonic dystrophy. Hum Mol Genet 15: 2087-2097, 2006.

31. Hao M, Akrami K, Wei K, De Diego C, Che N, Ku JH, Tidball J, Graves MC, Shieh PB and Chen F: Muscleblind-like 2 (Mbnl2)-deficient mice as a model for myotonic dystrophy. Dev Dyn 237: 403-410, 2008.

32. Miyazaki Y, Adachi H, Katsuno M, Minamiyama M, Jiang YM, Huang Z, Doi H, Matsumoto S, Kondo N, Iida M, et al: Viral delivery of miR-196a ameliorates the SBMA phenotype via the silencing of CELF2. Nat Med 18: 1136-1141, 2012.

33. Braunagel SC, Williamson ST, Ding Q, Wu X and Summers MD: Early sorting of inner nuclear membrane proteins is conserved. Proc Natl Acad Sci USA 104: 9307-9312, 2007.

34. Stumpo DJ, Byrd NA, Phillips RS, Ghosh S, Maronpot RR, Castranio T, Meyers EN, Mishina Y and Blackshear PJ: Chorioallantoic fusion defects and embryonic lethality resulting from disruption of $\mathrm{Zfp} 36 \mathrm{~L} 1$, a gene encoding a CCCH tandem zinc finger protein of the Tristetraprolin family. Mol Cell Biol 24: 6445-6455, 2004.

35. Yamazaki T, Kawamura Y, Minami A and Uemura $\mathrm{M}$ : Calcium-dependent freezing tolerance in Arabidopsis involves membrane resealing via synaptotagmin SYT1. Plant Cell 20: 3389-3404, 2008.

36. Poduri A, Chopra SS, Neilan EG, Elhosary PC, Kurian MA, MeyerE,Barry BJ,Khwaja OS, Salih MA,Stödberg T, et al:Homozygous PLCB1 deletion associated with malignant migrating partial seizures in infancy. Epilepsia 53: e146-e150, 2012.

37. Brems H, Chmara M, Sahbatou M, Denayer E, Taniguchi K, Kato R, Somers R, Messiaen L, De Schepper S, Fryns JP, et al: Germline loss-of-function mutations in SPRED1 cause a neurofibromatosis 1-like phenotype. Nat Genet 39: 1120-1126, 2007.

38. Kelly CE, Thymiakou E, Dixon JE, Tanaka S, Godwin J and Episkopou V: Rnf165/Ark2C enhances BMP-Smad signaling to mediate motor axon extension. PLoS Biol 11: e1001538, 2013.

39. Wink M: Molecular modes of action of cytotoxic alkaloids: from DNA intercalation, spindle poisoning, topoisomerase inhibition to apoptosis and multiple drug resistance. Alkaloids Chem Biol 64:1-47, 2007.

40. Mei L, Chen Y, Wang Z, Wang J, Wan J, Yu C, Liu X and Li W: Synergistic anti-tumour effects of tetrandrine and chloroquine combination therapy in human cancer: a potential antagonistic role for p21. Br J Pharmacol 172: 2232-2245, 2015.

41. Solomon VR and Lee H: Quinoline as a privileged scaffold in cancer drug discovery. Curr Med Chem 18: 1488-1508, 2011.

42. Cordell GA, Quinn-Beattie ML and Farnsworth NR: The potential of alkaloids in drug discovery. Phytother Res 15: 183-205, 2001. 